\title{
Confiança no Futuro
}

A Associação Brasileira de Polímeros promoveu, este ano, eleições para o Novo Conselho Diretor que escolheu a Diretoria para o biênio 2001-2003. Participarão da Nova Diretoria da ABPol os seguintes Conselheiros: Domingos Jafelice (DSM South America) como Presidente, Elias Hage Jr.(UFSCar/ DEMa) como Vice-Presidente e, como Diretores, Ailton de Souza Gomes (UFRJ/IMA), Francisco Ferraroli (Rhodia Poliamida Ltda.), Julio Harada (Basf S/A), Luiz Fernando D. Cassinelli (OPP Petroquímica), Luiz Henrique C. Mattoso (Embrapa), Raquel S. Mauler (UFRGS/IQ) e Sebastião V. Canevarolo Jr. (UFSCar/DEMa).

Nesta edição a Revista "Polímeros: Ciência e Tecnologia" trás uma entrevista com o futuro presidente da ABPol, Domingos Jafelice que sucederá o atual presidente, Silvio Manrich, no dia 15 de novembro, durante o $6^{\circ}$ Congresso Brasileiro de Polímeros que acontece em Gramado, RS.

Qual sua trajetória profissional até ocupar a posição de Diretor da DSM? O que o levou a trabalhar na área de polímeros?

Iniciei minha trajetória profissional na Dow Química como TS\&D em Plásticos. Após 3 anos, optei por ampliar minha experiência na área de transformação de polímeros, sendo então contratado pela Arno (fabricante de eletrodomésticos) como Chefe do Laboratório de Plásticos, onde permaneci por outros 3 anos. Em 1984 ingressei na Nitriflex onde assumi a posição de Gerente de Assistência Técnica e logo após a Gerência de Vendas de Plásticos. Em 1996 fui contratado pela DSM onde acumulo as posições de Gerente de Marketing e Vendas de Elastômeros e a Diretoria da DSM South America. Minha opção pela área de polímeros foi pautada pela minha inclinação a aceitar os desafios de uma tecnologia considerada nova no país.

\section{O que faz com que dirigentes}

de várias empresas da área atuem junto a ABPol?

No meu caso, a intenção de agregar mais valor às atividades empresariais, ampliar o domínio tecnológico e a rede de contatos e contribuir de modo efetivo para que o conhecimento possa ser permeado para a sociedade.

\section{Como foi sua experiência} como Diretor de Marketing da ABPol no últimos dois anos?

Muito construtiva e desafiadora. As atividades da ABPol são muito importantes para o meio científico e empresarial e seus profissionais, mas a visibilidade da ABPol é ainda limitada, o que afeta sua missão de permear e divulgar o conhecimento na comunidade. Temos ainda um longo caminho a trilhar nesse aspecto, que merecerá elevada prioridade da nova Diretoria eleita.

\section{Eleito como presidente da}

ABPol, quais são as perspectivas para os próximos anos?

Apesar da perspectiva economico-financeira projetada para o Brasil para os próximos 2-3 anos não ser muito positiva por uma série de fatores externos, a ABPol tem a chance histórica de crescer, expandir sua área de influência e consolidar seu nome nesse período. Há inegável necessidade de ampliar o portifólio de associados e boas possibilidades de abrir o espectro geográfico, por exemplo, reforçando nossa posição no Norte e Nordeste. Existe também um potencial imenso a ser explorado no setor de transformação de polímeros, onde a ABPol tem hoje uma presença tímida.

A ABPol tem cumprido sua missão junto à comunidade (empresas, universidades e centros de pesquisas)? $O$ que pode ser implementado para o crescimento da interação entre essas instituições? 
Sim. Considerando que a ABPol está completando 13 anos de atividades, as conquistas junto à universidades, centros de pesquisas e empresas, têm sido significativas. Um exemplo disso é a evolução dos cursos e treinamentos oferecidos pela $\mathrm{ABPol}$, a valorização de nossa revista e o excepcional crescimento dos Congressos Brasileiros de Polímeros. A interação poderá ser ainda maior se a ABPol expandir sua área de influência, presença geográfica e comunicação.

Os profissionais formados na área de polímeros no Brasil atendem às necessidades das empresas ou realmente é necessário investir em novos campos de especialidades?

O meio empresarial brasileiro, fortemente pressionado pela globalização, limitações de escala e questões tributárias, é muito dinâmico. Consequentemente, suas necessidades são também dinâmicas e mutantes. Os profissionais formados na área de polímeros no Brasil têm atendido razoavelmente a necessidade básica das empresas mas, o sucesso do passado não representa passaporte para o futuro. Há necessidade premente de investir em no- vos campos de especialidades, pois as necessidades empresariais estão em rápida mutação. O segmento de transformação de plásticos, apenas para citar um exemplo, passa por uma fase de modernização, automação e racionalização tão intensa que a demanda por profissionais da área de polímeros tem mudado, apresentando um perfil diferenciado cuja diversificação atinge do "chão de fábrica" à alta administração. A ABPol tem papel importante no suporte dessas tendências e apoio na formação desse novo profissional que as empresas vão demandar num futuro mais próximo do que se imagina.

Como você vê a representatividade da ABPol no mundo globalizado?

A ABPol tem reforçado sua representatividade global, especialmente nos últimos 8 anos. A indexação da nossa revista pela Chemical Abstracts e RAPRA, o intercâmbio de informações com outras entidades internacionais e a forte presença estrangeira no CBPol e outros congressos organizados pela $\mathrm{ABPol}$ são exemplos inequívocos desse fenômeno. A recente interação com a SPE

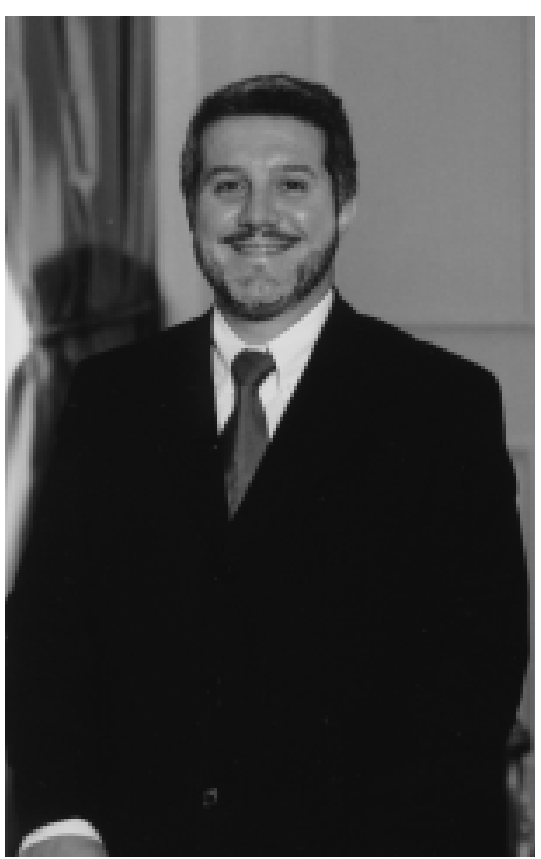

(Society of Plastics Engineers) comprova os bons resultados obtidos pela $\mathrm{ABPol}$ nesse sentido.

\section{Qual sua mensagem aos só- cios da ABPol?}

Minha mensagem final é de confiança no futuro. A ABPol tem a oportunidade de crescer e ganhar importância no Brasil e no mundo nos próximos anos. Vamos aproveitá-la! O apoio dos sócios da associação através de ações individuais ou do Conselho é essencial para que esse desafio seja vencido! 